\title{
Effect of Flour Changes Due to Storage on Kasutera Cake Volume
}

\author{
Chieko NaKamura ${ }^{1}$, Yoshiki Koshikawa ${ }^{2}$ and Masaharu Seguchi ${ }^{3}$ \\ ${ }^{1}$ Kobe Women's Junior College, Chuoo-ku, Kobe City 650-0046, Japan \\ ${ }^{2}$ Masuda Flour Milling Co., Ltd., Nagata-ku, Kobe City 653-0021, Japan \\ ${ }^{3}$ Faculty of Home Economics, Laboratory of Food Technology, Kobe Women's University, Suma-Ku, Kobe City 654-8585, Japan
}

Received October 27, 2006; Accepted June 3, 2007

\begin{abstract}
Four kinds of soft wheat flours, Takaragasa gold, Furian, Tokutakaragasa and Aokoma (protein 9.06, 9.30, 9.69 and $10.17 \%$, respectively), which were commercially used for sugar- and protein-rich Kasutera cake, were stored at room temperature $\left(15-25^{\circ} \mathrm{C}\right)$ for $2,4,6,8,10$ and 12 months. A Kasutera cake baking test with these stored wheat flours showed that the volume $\left(\mathrm{cm}^{3}\right)$ of Kasutera cake was gradually increased with elapse of storage period. These wheat flours were fractionated into water solubles, gluten, prime starch (A starch granule) and tailings (mixture of water insoluble proteins, polysaccharides, lipids and B starch granule) fractions using an acetic acid fractionation technique. A gradual increase of the interaction between prime starch and tailings fractions could be observed from the inclusion of the prime starch to the tailings fractions in each wheat flour with storage. It was found that the increase of volume of the Kasutera cake was highly related to the interaction between the prime starch and tailings fractions in the stored wheat flours. Mixograph profiles showed that the hydrophobicity of the wheat flour depended on the storage period. RVA (Rapid Visco Analyser) profiles of these stored wheat flours showed that the onset time became earlier and the peak viscosity increased, likely due to the hydrophobic interaction of flour components.
\end{abstract}

Keywords: stored wheat flour, Kasutera cake volume, flour changes

\section{Introduction}

Kasutera cake has been a favorite in Japan since it was first introduced to Japan from Portugal in the $1500 \mathrm{~s}$. While Kasutera cake is called "pao de lo" in Portuguese, the origin of the Japanese name is still unclear (Kariyazono, 2004). Kasutera cake $(100 \mathrm{~g})$ is composed of $25.6 \mathrm{~g}$ moisture, $6.2 \mathrm{~g}$ protein, $4.6 \mathrm{~g}$ fat, $63.2 \mathrm{~g}$ carbohydrate and 0.4 $\mathrm{g}$ ash. The formula is composed of $100 \%$ soft wheat flour, $176 \%$ sugar, $159 \%$ whole egg, $32 \%$ egg yolk, $52 \%$ liquid sugar, $24 \%$ honey and $40 \%$ water; the formula is very complex and the leavening of the cake is due to the air that is trapped by the egg protein during mixing. It is traditionally known, through oral instruction, that to make an excellent Kasutera cake, storage of the wheat flour for a number of months at room temperature is necessary; fresh flour results in a poorer texture. The reason for the difference has remained unclear. AaltoKaarlehto et al. (1993) showed a mathematical model of effect of storage time and storage temperature on the pasting properties of a hard winter wheat flour. Seguchi (1990), Seguchi et al. (1998), and Ozawa and Seguchi (2006) reported that dry heated wheat flour $\left(\right.$ at $120^{\circ} \mathrm{C}$ ) and stored wheat flour (room temperature- $100^{\circ} \mathrm{C}$ ), respectively, improved pancake springiness, and that the improvement may be due to the interaction between the prime starch

* To whom correspondence should be addressed.

E-mail: seguchi@suma.kobe-wu.ac.jp and tailings fractions in these wheat flours. Furthermore, it was reported that the physical interaction between prime starch and tailings fractions may be caused by the change of the starch granule surface protein from hydrophilic to hydrophobic due to aging at room temperature (Seguchi et al., 1993) and dry heating (Seguchi, 1984 and 1990) of wheat flour. In proteins, surface hydrophobicity generally increases upon heating (Tanford, 1980; Wicker et al., 1986; Voutsinas et al., 1983; Matsudomi et al., 1982; Deshpande and Damodaran, 1989). Chen and Schofield (1996) reported that changes in glutathione levels are closely related to changes in breadmaking performance during the short-term storage of white flour. Pomeranz (1992) summarized maturation is due to an increase in the number of sulfoxide bonds in gluten and it is caused by free, unsaturated fatty acids.

Since egg white protein functionality is a critical factor for Kasutera cake quality, pancake baking (Seguchi and Matsuki, 1977) with an egg-free formulation cannot be used as an alternative baking method for predicting Kasutera cake texture. The bubble film in Kasutera cake is mainly composed of egg white protein (Kariyazono, 2004) and the role of wheat flour protein in the film may be small, with wheat flour acting only as a cement between the bubbles. However, it has been experientially shown that stored wheat flour effects an improvement of the texture of Kasutera cake, in spite of the lower composition percentage, in terms of formula, than pancakes. This 
suggests that the real role of wheat flour in Kasutera cake may have been masked. In this experiment, in order to clarify the mechanism of storage of the flour on Kasutera cake, four kinds of soft wheat flour for Kasutera cake were subjected to storage at room temperature for 12 months, and Kasutera cake baking was performed with these wheat flours. The four wheat flours were also fractionated into water solubles, gluten, tailings and prime starch fractions by acetic acid fractionation, and it was ascertained whether an interaction between the prime starch and tailings fractions occurred or not. Furthermore, we obtained new data on stored flour through analysis of the rheological changes in these flours by mixograph and RVA tests.

\section{Materials and Methods}

Wheat flour Takaragasa gold, Furian, Tokutakaragasa and Aokoma wheat flours were donated by Masuda Flour Milling Co., Ltd., Kobe, Japan. Protein conversion was N $\times$ 5.7 (AACC method 46-10, 2000), and ash was determined according to the AACC method (08-01, 2000). General analysis of these flours is shown in Table 1.

Storage of wheat flour Wheat flour $(1 \mathrm{~kg})$ was placed on an iron plate $(25 \times 34,3-\mathrm{cm}$ height), and stored in the shade at room temperature $\left(15-25^{\circ} \mathrm{C}\right)$ for $2,4,6,8,10$ and 12 months. Samples were not protected from moisture changes during storage. After storage, samples were kept at $-20^{\circ} \mathrm{C}$.

Kasutera cake baking Whole eggs (266 g), egg yolks (53g), sugar (294g), liquid sugar (87g), honey (40 g) and water $(67 \mathrm{~mL})$ were mixed and slightly homogenized with warming to $35^{\circ} \mathrm{C}$ in a Kitchen Aid mixer (Kenmix Chef Aicoh Mixers \& Aicoh Systems Co., Ltd., Japan). The mixture was homogenized for $1 \mathrm{~min}$ at a speed of $128 \mathrm{rpm}$ and $10 \mathrm{~min}$ at $75 \mathrm{rpm}$ at room temperature. The specific gravity (tanehijyu) of the mixture was 0.52. Wheat flour (dry weight, $167 \mathrm{~g}$ ) was added to the mixture and homogenized for $5 \mathrm{~min}$ at a speed of $48 \mathrm{rpm}$. The specific gravity (kijihijyu) and temperature of the batter were 0.58 -0.60 and $25^{\circ} \mathrm{C}$, respectively. The batter was poured into a paper-laid Kasutera case $(22.3 \times 18.8,7.0$-cm height), which was made with a wooden frame and iron-bottom, and was placed in an oven $\left(230^{\circ} \mathrm{C}\right.$ upper; $200^{\circ} \mathrm{C}$ bottom $)$ for $90 \mathrm{sec}$. Next, the batter was removed from the oven and stirred with a rubber spatula for $30 \mathrm{sec}$ to obtain uniformity (awakiri) and baked for a further $90 \mathrm{sec}$ in the same manner. After this treatment (awakiri) was repeated three times, the batter was baked for $8 \mathrm{~min}$. Next, two sets of the same wooden frame were piled upon the Kasutera frame and covered with an iron lid. The batter was further baked for $25 \mathrm{~min}$. Kasutera cake volume $\left(\mathrm{cm}^{3}\right)$ was measured by rapeseed displacement (AACC Method 10-10B, 2000). Changes in the volume of the Kasutera cake were intermittently measured for $3 \mathrm{~h}$ after removing it from the oven. The moisture content of the Kasutera cake was measured with a moisture determination balance FD-600 (Kett Electric Laboratory Co. Ltd., Tokyo, Japan).

Fractionation of wheat flour with acetic acid ( $p H$ 3.5) Wheat flour was fractionated using the method of Seguchi
Table 1. Genaral analysis of wheat flours (Takaragasa gold, Furian, Tokutakaragasa, and Aokoma).

\begin{tabular}{lcccc}
\hline \multirow{2}{*}{ Flour } & Protein(\%)* & Ash(\%)* & \multicolumn{2}{c}{ IMC(\%) } \\
\cline { 5 - 6 } & & & Omonth & 12months \\
\hline Takaragasa gold & $9.06 \pm 0.01$ & $0.42 \pm 0.02$ & 11.8 & 14.2 \\
Furian & $9.30 \pm 0.00$ & $0.39 \pm 0.01$ & 13.3 & 13.4 \\
Tokutakaragasa & $9.69 \pm 0.06$ & $0.43 \pm 0.01$ & 12.9 & 13.2 \\
Aokoma & $10.17 \pm 0.10$ & $0.45 \pm 0.01$ & 12.9 & 13.2 \\
\hline $\begin{array}{l}{ }^{1} \text { MC: Moisture contont. } \\
\text { * Bssed on dry basis. }\end{array}$ & & & \\
\hline
\end{tabular}

et al. (1998). The homogenization step was performed using a mortar and pestle (Nittokagaku Co. Ltd., ANM-150 Type, Japan; rpm of the mortar and pestle were 120 and 70 , respectively). Flour (50 g) was mixed with $150 \mathrm{~mL}$ of water and homogenized for $20 \mathrm{~min}$ at room temperature. After centrifugation at $1700 \times \mathrm{g}(3000 \mathrm{rpm})$ for $20 \mathrm{~min}$ at room temperature, the supernatant was freeze-dried to recover the water soluble fraction. The precipitate was homogenized in $125 \mathrm{~mL}$ of $0.136 \mathrm{~N}$ acetic acid solution ( $\mathrm{pH}$ 3.5) for $20 \mathrm{~min}$ and centrifuged. The resulting precipitate was further homogenized in $75 \mathrm{~mL}$ of $0.0283 \mathrm{~N}$ acetic acid solution (pH 3.5) and centrifuged. The two supernatants after centrifugation were combined and freeze-dried to recover the gluten fraction. The precipitate was homogenized in $150 \mathrm{~mL}$ of water and the $\mathrm{pH}$ was adjusted to 5.0 with $5 \mathrm{~N}$ $\mathrm{NaOH}$ solution. After centrifugation, two layers of the precipitate appeared; the upper yellowish and viscous layer was the tailings fraction, while the white layer in the bottom was the prime starch fraction. The fractions were collected separately with a spatula and were air-dried and recovered.

RVA (Rapid visco analyser) test Wheat flour (moisture content $14 \%$ ) $4 \mathrm{~g}$ and $25 \mathrm{~mL}$ water were mixed and tested in a Rapid Visco Analyser-4 (RVA, New Scientific Pty. Ltd., Australia). The dry weight (3.4 g) and water (25.6 $\mathrm{mL}$ ) were adjusted in each sample.

Ten-gram mixograph test Ten grams of wheat flour (moisture content 14\%) and $5 \mathrm{~mL}$ water were mixed and tested in a 10-gram mixograph (National Mfg. Company, NB, USA). The dry weight $(8.6 \mathrm{~g})$ and water $(6.4 \mathrm{~mL})$ were adjusted in each sample. Mixing speed of the mixograph was $86 \mathrm{rpm}$.

Statistical analysis A statistical software package (SPSS Inc., Chicago, IL, USA) was used for the statistical analyses. Kasutera cake baking was performed twice with stored wheat flour and the volume was measured by rapeseed displacement and averaged. When the difference of volume of Kasutera cake was more than $10 \%$, further Kasutera cake baking was performed. Analysis produced significant $\mathrm{F}$ values by the analysis of variance, followed by Duncan's multiple range test for comparison of mean. 


\section{Results and Discussion}

Kasutera cake baking with stored wheat flour and its shrinkage after $180 \mathrm{~min}$ The Kasutera cake baking test was performed with stored wheat flour "Tokutakaragasa" (protein content: 9.69\%), which was the most popular flour in Japan for Kasutera cake baking. Fig. 1 shows the sectioned Kasutera cakes just after baking. The smaller volume of the control cake baked with fresh wheat flour was clearly due to collapse during baking. Fig. 2 shows the changes in volume of Kasutera cake baked with stored wheat flour, volume shrinkage after $180 \mathrm{~min}$ at room temperature, and their moisture contents. The moisture contents of Kasutera cake were within 31-37\%. The temperature in the center of Kasutera cake just after removal from the oven and after $180 \mathrm{~min}$ at room temperature were 104 and $33^{\circ} \mathrm{C}$, respectively. It was observed

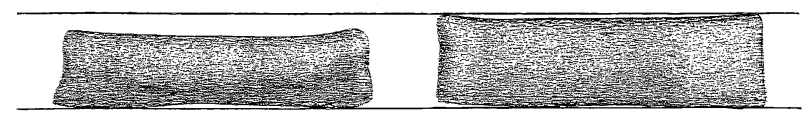

$-1 \mathrm{~cm}$

Fig. 1. Sectioned Kasutera cakes just after baking (left: baked with fresh Tokutakaragasa wheat flour; right: baked with stored wheat flour for 12 months). that the volume of the Kasutera cake increased over a storage period of 12 months, and the volume of each Kasutera cake gradually decreased and shrank with elapsed time of $180 \mathrm{~min}$ at room temperature; however, the level of shrinkage (75-80\%) was almost same for every Kasutera cake, so the order of volume of the Kasutera cake just after baking is same as that after $180 \mathrm{~min}$. Three other flours, Takaragasa gold, Furian and Aokoma, were stored at room temperature for 12 months and were subjected to Kasutera cake baking tests in which we used fresh flour and flour stored for 12 months. The increase in the volume of Kasutera cake baked with stored flour was remarkable in all samples; however, it was not clear that differences in flour protein content were related to the degree of these storage effects (Table 2). From these data, it was confirmed that the storage effect of wheat flour on the volume of Kasutera cake was observed in every wheat flour.

It is considered that the contribution of the stored wheat flour to the volume of the Kasutera cake may be due to an increase in the stability of air bubbles in Kasutera batter by the stored wheat flour. Thus, to investigate the reason the storage of wheat flour contributed to the stability of air bubble membrane of egg white protein in Kasutera batter, acetic acid fractionation of the stored wheat flour was performed. Seguchi et al.

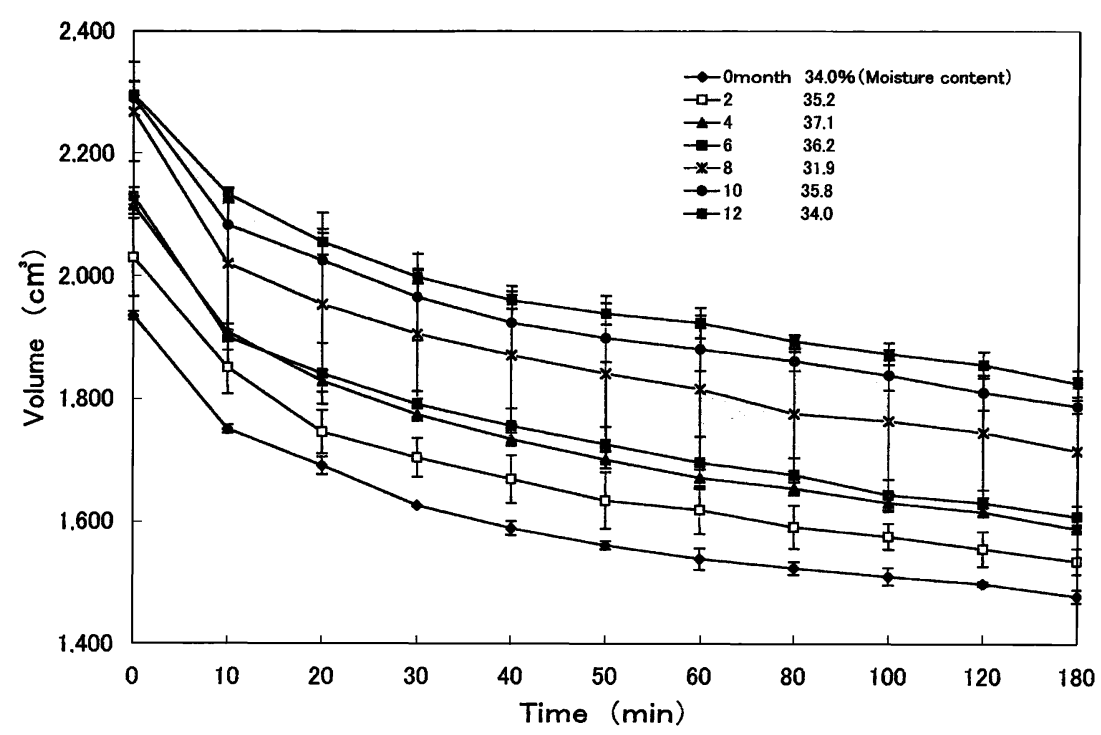

Fig. 2. Effects of storage of wheat flour (Tokutakaragasa) on the volume $\left(\mathrm{cm}^{3}\right)$ and moisture content of Kasutera cake, and changes of Kasutera cake after $180 \mathrm{~min}$ at room temperature.

Table 2. Effect of storage of wheat flours on the volume $\left(\mathrm{cm}^{3}\right)$ and moisture oontent (\%) of Kasutera, and change of volume after $180 \mathrm{~mm}$.

\begin{tabular}{|c|c|c|c|c|c|c|c|c|c|}
\hline \multirow{2}{*}{$\begin{array}{l}\text { storage } \\
\text { month }\end{array}$} & \multicolumn{3}{|c|}{ Takaragasa gold } & \multicolumn{3}{|c|}{ Furian } & \multicolumn{3}{|c|}{ Aokoma } \\
\hline & $\begin{array}{c}\text { Omin } \\
\mathrm{cm}\end{array}$ & $\begin{array}{c}180 \mathrm{~min} \\
\mathrm{cmi}\end{array}$ & $\begin{array}{c}\text { Moisture content } \\
\% \\
\end{array}$ & $\begin{array}{c}0 \mathrm{~min} \\
\mathrm{~cm}\end{array}$ & $\begin{array}{c}180 \mathrm{~min} \\
\mathrm{~cm}^{\prime}\end{array}$ & $\begin{array}{c}\text { Moisture content } \\
\%\end{array}$ & $\begin{array}{c}0 \mathrm{~min} \\
\mathrm{~cm}\end{array}$ & $\begin{array}{c}180 \mathrm{~min} \\
\mathrm{~cm}^{2}\end{array}$ & $\begin{array}{c}\text { Moisture content } \\
\% \\
\end{array}$ \\
\hline 0 & $2235(21.2)$ & $1730(42.4)$ & 33.8 & $1813(60.1)$ & $1338(10.6)$ & 33.6 & $2058(95.5)$ & $1565(14.1)$ & 33.2 \\
\hline 12 & $2518(74.2)$ & $1945(77.8)$ & 34.3 & 2295 (49.5) & 1778 (3.5) & 34.1 & $2195(7.1)$ & $1725(63.6)$ & 35.3 \\
\hline
\end{tabular}

Value represent means of 2 replicates with the standard deviation in parenthesis.

No range tests performed with fewer than three non-empty groups. 


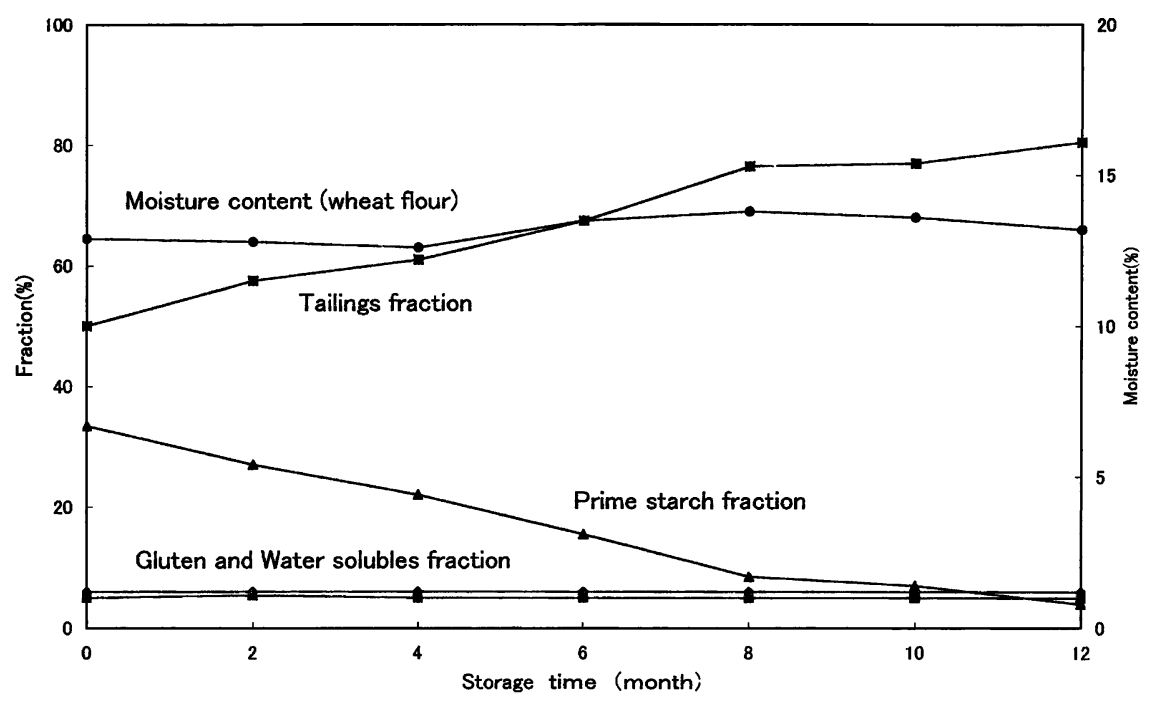

Fig. 3. Results of moisture content, acetic acid fractionation of Tokutakaragasa flour stored at room temperature for $0,2,4,6,8,10$ and 12 months.

(1998) and Nakamura and Seguchi (2007) reported that there was a strong relationship between pancake springiness and the interaction between the prime starch and tailings fractions in stored wheat flour. Nakamura and Seguchi (2007) suggested that the improvement in the springiness of pancakes made with stored wheat flour was caused by firm structure of gas cells, which are solely the result of the hydrophobic interactions of flour. In Kasutera cake baking, the leavening of Kasutera cake is due to the bubble film of the egg white protein and is different from the leavening of egg-free pancake baking; thus, it was not clear whether the increase in the volume of Kasutera cake made with stored wheat flour was related to the interaction between the prime starch and tailings fractions.

Acetic acid fractionation of wheat flour The results of moisture content analysis of stored Tokutakaragasa flour and the acetic acid fractions are shown in Fig. 3. The moisture content of wheat flour was almost constant throughout the 12-month period, while the recovery of water solubles $(4.9 \%)$ and gluten $(6.1 \%)$ fractions was almost constant. However, the tailings and prime starch fractions, which were 50.2 and $33.6 \%$ in fresh flour, changed to 80.4 and $3.8 \%$ after 12 months, respectively, indicating that a greater tailings fraction resulted from flour fractionation as time progressed, resulting in decreased prime starch fraction ( $\mathrm{w} / \mathrm{w}$ basis) after storage that could not be separated by centrifugation (Fig. 3).

Takaragasa gold, Furian and Aokoma flour (Table 1) were subjected to the same experiments. The results of acetic acid fractionation of the flour were almost identical; water solubles and gluten fractions were practically unchanged, but the tailings fraction increased and the prime starch fraction decreased, indicating the occurrence of an interaction between the prime starch and tailings fractions during storage. Seguchi (1993) reported that the occurrence of hydrophobicity of prime starch granule surface protein in aged wheat flour caused the interaction between prime starch and tailings fractions. Kusunose et al. (2002), using 8 kinds of various protein containing wheat flour stored at $60^{\circ} \mathrm{C}$, suggested that certain wheat proteins are related to the binding of prime starch to tailings fraction in stored wheat flour and may act as a binder. From our results of Kasutera cake baking tests and acetic acid fractionation of these four flours, it was suggested that storage of flour at room temperature could cause an interaction between the prime starch and tailings fractions and thereby giving a higher volume of Kasutera cake. The correlation coefficients ( $r$ ) between the volume of the Kasutera cake and the recovery (\%) of prime starch fraction, and between the tailings fraction of Tokutakaragasa flour were calculated. The value of (r) between the volume and prime starch fraction was -0.99 , and that between volume and tailings fraction was +0.99 . These data indicated that the interaction between the tailings and prime starch fractions was highly related to the increase of volume of Kasutera cake. Although the presence of hydrophobicity due to storage in wheat flour was shown through a mixograph and RVA tests by Nakamura and Seguchi (2007), we ascertained the rheological changes occurring in stored wheat flours through prime starch and tailings fractions.

Mixograph and RVA tests of stored wheat flour Figure 4 indicates the mixograph profiles of Tokutakaragasa flour that were stored for 12 months at room temperature. Large swings in the early stage of the mixograph profile could be observed when dough was coiled around the mixograph pins, and proceeded to lower constant swings in fresh wheat flour. However, stored flours were difficult to coil around the pins, and it took a longer time until coiling to large swinging began, which indicated the occurrence of hydrophobicity of flour due to storage. Seguchi (1993) reported that starch granules fractionated from wheat flour aged at $25^{\circ} \mathrm{C}$ for 202 days, or at higher temperatures for a shorter time, exhibited increased hydrophobicity (lipophilization) and contained more starch granule 


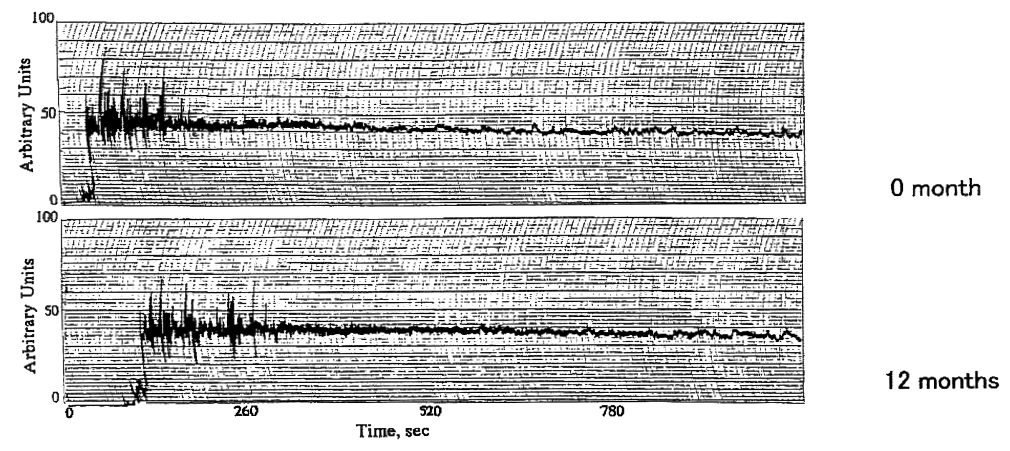

Fig. 4. Effects of storage of Tokutakaragasa flours on mixograph profiles at room temperature for 12 months.

surface protein.

RVA profiles of Tokutaragasa flour, stored for 2, 4, 6, 8, 10 or 12 months at room temperature were observed (data not shown). The peak viscosity of RVA increased and the onset time of swelling decreased with the elapsed storage period, which is considered to be due to an interaction between the prime starch and tailings fractions (Nakamura and Seguchi, 2007). The other flours (Takaragasa gold, Furian and Aokoma) showed the same results.

It is considered that egg white protein in Kasutera batter was denatured by vigorous mixing and a hydrophobic air bubble membrane that could absorb stored wheat flour through hydrophobic interaction was formed. As the air bubble stabilized, an increased volume of Kasutera cake could be obtained. However, as wheat protein such as gluten would lose its viscoelasticity during storage, wheat protein did not contribute to the volume of Kasutera cake. Thus, the leavening of Kasutera cake was only due to the air bubbles of egg white membrane. It was reported by Seguchi et al. (1998) that the leavening of pancake baked without egg white protein was solely due to wheat protein, as the volume of the pancake decreased when baked with stored wheat flour despite an increase in springiness. They considered that the increase in springiness was due to the strengthening of pancake structure by the interaction of prime starch and tailings fractions.

\section{Conclusions}

It was observed that the storage of Kasutera wheat flour at room temperature led to an interaction between the prime starch and tailings fractions in flour, resulting in an increase in the volume of Kasutera cake. Mixograph and RVA tests suggested that the hydrophobicity of stored wheat flour is increased, and hydrophobic flour is attracted to the air bubble hydrophobic membrane, resulting in the formation of a stable membrane and an increase in the volume of Kasutera cake.

\section{References}

Aalto-Kaarlehto, T., Antila, J. and Yli-Kyyny, M. (1993). Effect of storage time and storage temperature on pasting properties of a hard winter wheat flour-a mathematical model. Proceedings of the 25th Nordic Cereal Congress, 266-269.
American Association of Cereal Chemists. (2000). Approved Methods of the AACC, 10th Ed. Method 08-01, 10-10B and 4610. The Association: St. Paul, Minn.

Chen, X. and Schofield, J.D. (1996). Changes in the glutathione content and breadmaking performance of white wheat flour during short-term storage. Cereal Chem., 73, 1-4.

Deshpande, S.S. and Damodaran, S. (1989). Heat-induced conformational changes in phaseolin and its relation to proteolysis. Biochim. Biophys. Acta, 998, 179-188.

Kariyazono, A. (2004). In: Science of Castella (Japan). Korin: Tokyo. Kusunose, C., Noguchi, S., Yamagishi, T. and Seguchi, M. (2002). Binding of prime starch to tailings fraction by proteins in stored wheat flour. Food Hydrocolloids, 16, 73-77.

Matsudomi, N., Kato, A. and Kobayashi, K. (1982). Conformation and surface properties of deamidated gluten. Agric. Biol. Chem., 46, 1583-1586.

Nakamura and Seguchi (2007). Studies of improving effects of stored wheat flour on pancake texture. Food Sci. and Technol. Res., Accepted.

Ozawa, M. and Seguchi, M. (2006). Relationship between pancake springiness and interaction of wheat flour components caused by dry heating. Food Sci. and Technol. Res., 12, 167-172.

Pomeranz, Y. (1992). Biochemical, functional and nutritive changes during storage. In: Sauer, D.B. (ed.). Storage of Cereal Grains and their Products, pp. 55-143. American Association of Cereal Chemists, Inc.: St. Paul, Minn.

Seguchi, M and Matsuki, J. (1977). Studies on pancake baking I. Effect of chlorination of pancake qualities. Cereal Chem., 54, 287299.

Seguchi, M. (1984). Oil-binding ability of heat-treated wheat starch. Cereal Chem., 61, 248-250.

Seguchi, M. (1990). Effect of heat-treatment of wheat flour on pancake springiness. J. Food Sci., 55, 784-785.

Seguchi, M. (1993). Effect of wheat flour aging on starch-granule surface proteins. Cereal Chem., 70, 362-364.

Seguchi, M., Hayashi, M., Kanenaga, K., Ishihara, C. and Noguchi, S. (1998). Springiness of pancake and its relation to binding of prime starch to tailings in stored wheat flour. Cereal Chem., $\mathbf{7 5}$, $37-42$.

Tanford, C. (1980). The hydrophobic effect: formation of micelles and biological membranes. Wiley-Interscience, John Wiley \& Sons: New York.

Voutsinas, L.P., Nakai, S. and Harwalkar, V.R. (1983). Relationships between protein hydrophobicity and thermal functional properties. Can. Inst. Food Sci. Technol. J., 16, 185-190.

Wicker, L., Lanier, T.C., Hamann, D.D. and Akahane, T. (1986). Thermal transitions in myosin-ANS fluorescence and gel rigidity. J. Food Sci., 51, 1540-1543, 1562. 